\title{
Prevalence of Human Papillomavirus Types in Cervical Lesions From Women in Rural Western India
}

\author{
Kedar Deodhar, ${ }^{1 \dagger}$ Tarik Gheit, ${ }^{2 \dagger}$ Salvatore Vaccarella, ${ }^{2}$ Christine Carreira Romao, ${ }^{2}$ Vanessa Tenet, ${ }^{2}$ \\ Bhagwan M. Nene, ${ }^{3}$ Kasturi Jayant, ${ }^{3}$ Rohini Kelkar, ${ }^{1}$ Sylla G. Malvi, ${ }^{3}$ Bakary S. Sylla, ${ }^{2}$ \\ Silvia Franceschi, ${ }^{2}$ Jose Jeronimo, ${ }^{4}$ Surendra Shastri, ${ }^{1}$ Rengaswamy Sankaranarayanan, ${ }^{2}$ \\ and Massimo Tommasino ${ }^{2 *}$ \\ ${ }^{1}$ Tata Memorial Center, Tata Memorial Hospital \& Cancer Research Institute, Mumbai, India \\ ${ }^{2}$ International Agency for Research on Cancer, Lyon, France \\ ${ }^{3}$ Nargis Dutt Memorial Cancer Hospital (NDMCH), Barshi, India \\ ${ }^{4}$ Program for Appropriate Technology in Health (PATH), Seattle
}

Cervical cancer is the most common cancer among women in many areas of India which contributes for a fifth of the global burden of disease. Persistent infection with one of the high-risk human papillomaviruses (HPV) has been established as the cause for cervical cancer and the documentation of the prevalence of HPV types in cervical cancer in different regions of India is useful for a prevention program combining both screening and vaccination. In this study, the HPV type distribution and the frequency of $\mathrm{p} 16^{\mathrm{INK} 4 \mathrm{a}}$ immunoexpression have been determined in 125 cases of inflammatory lesions or grade 1 cervical intraepithelial neoplasia, 74 cases of grade 2, 72 cases of grade 3 , and 113 cervical cancer cases diagnosed among women from rural Solapur and Osmanabad districts, Maharashtra. The overall prevalence of high-risk HPV was $37.6 \%$ in inflammatory lesions or grade 1 cervical intraepithelial neoplasia, $63.5 \%$ in grade $2,97.2 \%$ in grade 3 and $92 \%$ in cervical cancer cases. HPV 16 and HPV 18 were detected in $80.6 \%$ of grade 3 cervical intraepithelial neoplasia and $86.5 \%$ of cervical cancer cases. $94.7 \%$ of the cervical cancer and $84.4 \%$ of the high grade lesions with a strong and full thickness staining for p16 $16^{\text {INK4a }}$ were positive for HPV infection; p16 $16^{\mathrm{INK} 4 \mathrm{a}} \mathrm{immu}$ noexpression increased with worsening grade of cervical intraepithelial neoplasia. The HPV genotyping data showing a high HPV 16 and 18 prevalence in cancer specimens indicate that prophylactic HPV 16/18 vaccination would have a significant impact on the prevention of cervical cancer in India. J. Med. Virol. 84:10541060, 2012. 다 2012 Wiley Periodicals, Inc.

\section{KEY WORDS: multiplex PCR/APEX assay; India; cervical cancer; HPV pre- valence; HPV vaccination}

\section{INTRODUCTION}

Cervical cancer is the second most common cancer in women in the world accounting for an estimated 530,000 new cases and 275,000 deaths around 2008 globally; a fifth of the global burden of disease is experienced in India which remarkably lacks cervical screening program and wide spread practice of screening, currently the most effective and feasible strategy for prevention [Ferlay et al., 2010; Sankaranarayanan, 2012]. Despite the fact that cervix cancer is the most preventable of all cancers both by primary prevention and by early detection of its precursor lesions, namely high-grade cervical intraepithelial neoplasia (CIN 2-3), it is the most common cancer

Grant sponsor: Bill \& Melinda Gates Foundation, Seattle, USA; Grant sponsor: Program for Appropriate Technology in Health (PATH), Seattle, USA; Grant sponsor: European Commission; Grant number: HPV-AHEAD (FP7-HEALTH-2011282562).

†Kedar Deodhar and Tarik Gheit contributed equally to this work.

*Correspondence to: Massimo Tommasino, Infections and Cancer Biology Group, International Agency for Research on Cancer, 150 cours Albert-Thomas, 69372 Lyon Cedex 08, France. E-mail: icb@iarc.fr

Accepted 20 March 2012

DOI 10.1002/jmv.23310

Published online in Wiley Online Library

(wileyonlinelibrary.com). 
among women in rural areas of India [National Cancer Registry Program of India, 2011].

Persistent infection with one of the mucosal highrisk (HR) human papillomavirus (HPV) types is the necessary cause of invasive cervical cancer and its precursor lesions, and they are detectable in approximately more than $90 \%$ of cervical cancer specimens and in more than $60 \%$ of precursor lesion tissues [IARC, 2007; Smith et al., 2007; Li et al., 2011; Walboomers et al., 1999]. The HR HPV 16 and HPV 18 are the most carcinogenic types, and are responsible for approximately $50 \%$ and $20 \%$, respectively, of cervical cancers worldwide. In addition to HPV 16 and HPV 18, additional HPV types appear to be involved in cervical carcinogenesis. In a recent evaluation, the International Agency for Research on Cancer (IARC) has concluded that there is sufficient evidence for the classification of HPV 31, 33, 35, 39, $45,51,52,56,58,59$, and 66 as human carcinogens [Cogliano et al., 2005; IARC, 2007; Schiffman et al., 2009].

In the last two decades, many studies have contributed to the development of a HPV prophylactic vaccine, which is based on virus-like particles (VLPs) assembled from recombinant main capsid protein L1 produced in eukaryotic systems. Two prophylactic HPV vaccines are commercially available so far, Gardasil and Cervarix, which differ in their composition. In fact, HPV 16 and HPV 18 VLPs are included in both vaccines, while Gardasil also contains VLPs from the low-risk HPV 6 and 11 [Villa et al., 2006; Einstein et al., 2009; Romanowski et al., 2009; Lu et al., 2011]. Several clinical trials have evaluated the safety and effectiveness of this vaccine, which showed high efficacy in preventing the development of cervical pre-malignant lesions caused by the vaccine included HPV types, inducing a robust response in immunized individuals and providing protection for at least 5 years [Villa et al., 2006; Einstein et al., 2009; Romanowski et al., 2009; Lu et al., 2011]. In addition, there is evidence that a certain level of cross-protection against non-vaccine HR HPV types is conferred by the two HPV vaccines [Lu et al., 2011]. Based on the initial data, it is expected that the implementation of the HPV 16/18 vaccine will have a profound impact on cervical cancer incidence, although it could vary among the different geographical areas. Indeed, epidemiological studies showed that the proportion of cervical cancer associated with specific HPV types can differ according to geographical areas. For instance, HPV 16 prevalence in cervical cancer ranges from $52 \%$ in Africa to $67 \%$ in Western/Central Asia, whereas HPV 18 was found in $14 \%$ and $20 \%$ of cervical cancers in Eastern Asia and in Africa, respectively [Li et al., 2011].

Despite the heaviest burden of cervical cancer in India, only limited data are available in this region on HPV prevalence in women with cervical neoplasia [Sankaranarayanan et al., 2008]. Different percentages of HPV 16-positive cancers were reported in various studies, ranking from 53.6\% in Bangalore (South India) to $65.2 \%$ in Delhi (North India) [Basu et al., 2009]. HPV16 was detected in $81.7 \%$ of cervical cancers in women of a rural area from central India (Wardha, Sevagram) [Gheit et al., 2009], using a highly sensitive and specific HPV typing method. However, whether this high HPV 16 prevalence is a feature of Central India or is also present in other Indian regions remains to be proven. In the present study, the prevalence of HPV infections was determined in cervical lesions from women from rural areas of Solapur district, Maharashtra state, Western India, using the same high-sensitive HPV typing method. In addition, the $\mathrm{p} 16^{\mathrm{INK} 4 \mathrm{a}}$ levels were evaluated as a surrogate marker of high-risk HPV infections, which could also be used as a complementary strategy to the current screening methods.

\section{MATERIALS AND METHODS}

\section{Specimen Collection}

Ten percent buffered formalin fixed paraffin blocks of biopsy specimens from 470 women with a histological diagnosis of inflammation and chronic cervicitis $(\mathrm{n}=68)$, squamous metaplasia $(\mathrm{n}=2)$, grade 1 cervical intraepithelial neoplasia (CIN1, $\mathrm{n}=63$ ), grade 2 cervical intraepithelial neoplasia (CIN 2, $\mathrm{n}=79$ ), grade 3 cervical intraepithelial neoplasia (CIN 3, $\mathrm{n}=75$ ) and cervical cancers (squamous cell carcinoma $\mathrm{n}=171$ and adenocarcinoma $\mathrm{n}=12$ ) were obtained from Nargis Dutt Memorial Cancer Hospital, Barshi, Maharashtra state, Western India. These women were participants in screening studies in Solapur and Osmanabad districts in Maharashtra, Western India, addressing the accuracy of Pap smear, visual inspection with acetic acid (VIA) and visual inspection with Lugol's iodine (VILI) in detecting cervical neoplasia. The screening studies in these districts were reviewed and approved by the institutional review and ethics committees of the Tata Memorial Centre, Mumbai, India, and the International Agency for Research on Cancer of the World Health Organization (WHO-IARC), Lyon, France. All subjects have signed informed consent. The formalin fixed biopsy specimens obtained from these women were embedded in paraffin within $24 \mathrm{hr}$ to ensure long-term preservation. The biopsy specimens were processed and stained with hematoxylin-eosin for histopathology in the pathology laboratory at the Nargis Dutt Memorial Cancer Hospital, and histological diagnosis of the specimens was reported by a panel of pathologists at the Nargis Dutt Memorial Cancer Hospital and the Tata Memorial Centre during 2005-2007.

\section{Immunohistochemistry for $\mathrm{p}^{\mathrm{INK}} \mathrm{Ia}^{\mathrm{IN}}$}

Immunohistochemistry was performed according to the protocol provided with the CINtec Histology p16 $6^{\text {INK4a }}$ Kit (9511, mtmlabs) for the qualitative detection of the $\mathrm{p} 16^{\mathrm{INK} 4 \mathrm{a}}$ antigen on slides prepared from formalin-fixed, paraffin-embedded cervical biopsies. 
The kit contains a collection of ready-to-use reagents optimized for immunohistochemical staining of $\mathrm{p} 16^{\mathrm{INK} 4 \mathrm{a}}$. Briefly, slides were deparaffinized and then rehydrated before the staining procedure can be performed. For the antigen retrieval process, slides were placed in a preheated Epitope Retrieval Solution $\mathrm{pH} 9$ $\left(95-99^{\circ} \mathrm{C}\right)$ and maintained at this temperature for $10 \mathrm{~min}$ followed by a $20 \mathrm{~min}$ cool-down period at room temperature. After a brief rinse in distilled water, slides were immersed in Wash Buffer in preparation for immunostaining. Specimens were blocked with a peroxidase-blocking reagent for $5 \mathrm{~min}$, followed by 30 min incubation with $\mathrm{p} 16^{\mathrm{INK} 4 \mathrm{a}}$ antibody (Mouse anti-human). Slides were then incubated for $30 \mathrm{~min}$ with the visualization reagent followed by $5 \mathrm{~min}$ incubation with DAB. Slides were subsequently counterstained with hematoxylin, dehydrated, mounted with permanent mounting medium, and coverslipped. All steps, with the exception of the epitope retrieval, were performed at room temperature. Immunoreactivity was visualized by light microscopy.

The staining pattern for $\mathrm{p} 16^{\mathrm{INK} 4 \mathrm{a}}$ was graded in each lesion as follows: 1 for a negative staining, no basal p16 $6^{\mathrm{INK} 4 \mathrm{a}}$ staining; 2 for a weak or/and rare basal p16 ${ }^{\text {INK4a }}$ staining; 3 for a diffuse and moderately positive with only part of the cervix epithelial stained; and 4 for a strong and full thickness staining of $\mathrm{p} 16^{\mathrm{INK} 4 \mathrm{a}}$ in the cervix epithelium.

\section{Preparation of the Paraffin Sections and DNA Extraction}

All paraffin blocks were processed at IARC, Lyon. Three sections of $10 \mu \mathrm{m}$ were cut from each paraffin block. The blades have been frequently changed and the microtome extensively washed with DNA away (Dutscher, Brumath) to prevent the risk of crosscontamination between different specimens during the cutting. In addition, empty paraffin blocks have been cut every ten cancer specimens and blindly analyzed to monitor possible cross-contamination. No contamination was detected throughout the study.

DNA was prepared by incubating the paraffin tissue

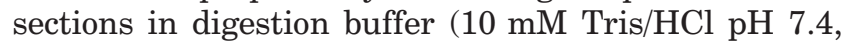
proteinase $\mathrm{K} 0.5 \mathrm{mg} / \mathrm{ml}$ and Tween $200.4 \%$ ) overnight at $37^{\circ} \mathrm{C}$. Samples were incubated for $10 \mathrm{~min}$ at $95^{\circ} \mathrm{C}$, centrifuged rapidly for $2 \mathrm{~min}$ at $15700 \mathrm{~g}$ in a bench centrifuge, and chilled on ice, to inactivate the proteinase $\mathrm{K}$ and to remove the paraffin. Finally, the aqueous phase was transferred to a new tube.

\section{HPV DNA Typing}

HPV typing was performed by the multiplex E7 PCR/APEX assay [Gheit et al., 2006]. The assay detects the DNA of 19 different alpha mucosal HPV types, that is, $16,18,26,31,33,35,39,45,51,52,53$, $56,58,59,66,68,70,73$, and 82 . Two primers for the amplification of $\beta$-globin were added to provide a positive control for the quality of the template DNA [Saiki et al., 1988].
Validation studies have been performed, in which the multiplex E7 PCR/APEX assay has been compared with several available HPV genotyping tests, including Linear Array and GP5+/6+ reverse line blot assay [Gheit et al., 2009; Eklund et al., 2010] and unpublished data.

\section{Statistical Analysis}

A valid result was defined as any sample with a positive $\beta$-globin result and only samples with a valid HPV typing result were included in the final analysis. The overall and type-specific prevalence of HPV positivity and the p16 $6^{\mathrm{INK} 4 \mathrm{a}}$ staining pattern was calculated for each grade of cervical lesion. The eight cases of adenocarcinoma were grouped with the squamous cell carcinoma for reporting the frequencies of HPV positivity and the p16 $6^{\mathrm{INK} 4 \mathrm{a}}$ staining pattern for invasive cervical cancer.

\section{RESULTS}

Out of a total of 470 cervical intraepithelial neoplasia and cervical cancer paraffin blocks, 86 samples were excluded from the study since they had poor quality/fragmented DNA and were found to be $\beta$-globin negative. The relative high percentage of inadequate specimens (approximately 20\%) was most likely due to procedure followed for tissue fixation.

In the remaining $384 \beta$-globin positive specimens, 125 were grade 1 cervical intraepithelial neoplasia or inflammatory lesions $(<\mathrm{CIN} 2$; mean age $=36.8$ years), 74 were grade 2 (mean age $=37.3$ years), 72 were grade 3 (mean age $=37.7$ years) and 113 were cervical cancers (squamous cell carcinoma $\mathrm{n}=105$ and adenocarcinoma $\mathrm{n}=8$, mean age $=42.3$ years). Overall, HPV-positivity gradually increased with the severity of the cervical disease, from $37.6 \%$ in grade 1 cervical intraepithelial neoplasia or inflammatory lesions (47/125); to $63.5 \%$ in grade $2(47 / 74)$ to $97.2 \%$ in grade $3(70 / 72)$ and $92.0 \%$ in cervical cancer specimens (104/113) (Table I).

HPV 16 was the predominant type present in all cervical lesions, from $32.8 \%$ in grade 1 cervical intraepithelial neoplasia or inflammatory lesions $(41 / 125)$ to $54.1 \%$ in grade $2(40 / 74), 76.4 \%$ in grade $3(55 / 72)$, and $76.1 \%$ in cervical cancer (86/113). The second most common type in cervical cancer specimens was HPV 18, followed by HPV 58 and 59. Conversely, HPV 33 was the second most common type observed in cervical intraepithelial neoplasia or inflammatory lesions. The rank of other types differed according to the grade of the lesion. The percentage of cases with HPV 16 or 18, alone or in co-infection with other types was $33.6 \%$ in grade 1 cervical intraepithelial neoplasia or inflammatory lesions, $55.4 \%$ in grade 2 , $77.8 \%$ in grade 3 , and $80.5 \%$ in cervical cancer (Table I). In grade 3 cervical intraepithelial neoplasia, and cervical cancer, the fraction of HPV 16/18 was substantially similar across different age groups (data not shown). 
TABLE I. Distribution of HPV Genotypes in Different Grades of Cervical Intraepithelial Neoplasia (CIN) and Cervical Cancer $(\mathrm{n}=384)$

\begin{tabular}{|c|c|c|c|c|c|c|c|c|}
\hline & \multicolumn{2}{|c|}{$<\mathrm{CIN} 2$} & \multicolumn{2}{|c|}{ CIN2 } & \multicolumn{2}{|c|}{ CIN3 } & \multicolumn{2}{|c|}{ Cancer } \\
\hline & Single & Total $(\%)$ & Single & Total (\%) & Single & Total (\%) & Single & Total (\%) \\
\hline All & 41 & 125 & 41 & 74 & 56 & 72 & 84 & 113 \\
\hline \multicolumn{9}{|l|}{ Age (years) } \\
\hline$<35$ & 17 & $46(36.8)$ & 17 & $27(36.5)$ & 17 & $22(30.6)$ & 8 & $12(10.6)$ \\
\hline $35-39$ & 16 & 39 (31.2) & 14 & $24(32.4)$ & 21 & $26(36.1)$ & 22 & $26(23.0)$ \\
\hline $40-44$ & 8 & $25(20.0)$ & 2 & $8(10.8)$ & 9 & $13(18.1)$ & 19 & 29 (25.7) \\
\hline$\geq 45$ & 0 & $15(12.0)$ & 8 & $15(20.3)$ & 9 & $11(15.3)$ & 35 & $46(40.7)$ \\
\hline Total HPV+ & 41 & 47 (37.6) & 41 & 47 (63.5) & 56 & $70(97.2)$ & 84 & $104(92.0)$ \\
\hline $\mathrm{HPV}-$ & - & $78(62.4)$ & - & $27(36.5)$ & - & $2(2.8)$ & - & $9(8.0)$ \\
\hline \multicolumn{9}{|l|}{ HPV type } \\
\hline 16 & 36 & $41(32.8)$ & 35 & $40(54.1)$ & 42 & $55(76.4)$ & 69 & $86(76.1)$ \\
\hline 18 & 0 & $3(2.4)$ & 0 & $1(1.4)$ & 1 & $3(4.2)$ & 3 & $12(10.6)$ \\
\hline 26 & 0 & 0 & 0 & 0 & 0 & 0 & 1 & $1(0.9)$ \\
\hline 31 & 0 & $1(0.8)$ & 1 & $1(1.4)$ & 1 & $2(2.8)$ & 2 & $2(1.8)$ \\
\hline 33 & 4 & $7(5.6)$ & 1 & $5(6.8)$ & 3 & $10(13.9)$ & 1 & $3(2.7)$ \\
\hline 35 & 0 & 0 & 0 & 0 & 1 & $2(2.8)$ & 0 & $1(0.9)$ \\
\hline 39 & 0 & 0 & 0 & 0 & 0 & 0 & 0 & $1(0.9)$ \\
\hline 45 & 0 & 0 & 0 & $1(1.4)$ & 2 & $3(4.2)$ & 1 & $3(2.7)$ \\
\hline 52 & 1 & $1(0.8)$ & 1 & $3(4.1)$ & 1 & $2(2.8)$ & 0 & $2(1.8)$ \\
\hline 53 & 0 & 0 & 0 & 0 & 0 & 0 & 1 & $1(0.9)$ \\
\hline 56 & 0 & 0 & 1 & $1(1.4)$ & 0 & 0 & 0 & $2(1.8)$ \\
\hline 58 & 0 & 0 & 1 & $1(1.4)$ & 2 & $4(5.6)$ & 2 & $5(4.4)$ \\
\hline 59 & 0 & 0 & 0 & 0 & 0 & $1(1.4)$ & 1 & $4(3.5)$ \\
\hline 68 & 0 & $1(0.8)$ & 1 & $1(1.4)$ & 0 & 0 & 2 & $2(1.8)$ \\
\hline 70 & 0 & 0 & 0 & $1(1.4)$ & 0 & 0 & 0 & 0 \\
\hline 73 & 0 & 0 & 0 & 0 & 0 & 0 & 1 & $1(0.9)$ \\
\hline 82 & 0 & 0 & 0 & 0 & 3 & $4(5.6)$ & 0 & $1(0.9)$ \\
\hline 16 or 18 & - & $42(33.6)$ & - & $41(55.4)$ & - & $56(77.8)$ & - & $91(80.5)$ \\
\hline 16 or 18 alone & 36 & $40(32.0)$ & 35 & $41(55.4)$ & 43 & $54(75.0)$ & 72 & $84(74.3)$ \\
\hline
\end{tabular}

Table II displays the $\mathrm{p} 16^{\mathrm{INK} 4 \mathrm{a}}$ staining intensity across different categories of disease severity and HPV status. A clear gradient was observed across categories of cervical diseases, with a predominance of low levels of staining in women with grade 1 cervical intraepithelial neoplasia or inflammatory lesions, and a predominance of high levels of staining in women with grade 3 and cervical cancer. A strong and full thickness staining of $\mathrm{p} 16^{\mathrm{INK} 4 \mathrm{a}}$ in the cervix epithelium was observed in $8.8 \%$ of grade 1 cervical intraepithelial neoplasia or inflammatory lesions (11/125) and
$70.3 \%$ of the grades 2 and $3(102 / 145)$, whereas a negative staining was observed in $51.2 \%(64 / 125)$ of the low grade lesions and in $12.4 \%$ (18/145) of the high grade lesions.

Independently of the histopathological status, $56.6 \%(64 / 113)$ of the HPV negative samples were also negative for $\mathrm{p} 16^{\mathrm{INK} 4 \mathrm{a}}$ staining, whereas $27.4 \%$ $(31 / 113)$ showed a rare basal p16 ${ }^{\mathrm{INK} 4 \mathrm{a}}$ staining, $9.7 \%$ (11/113) a diffuse and moderately positive staining, and $7 \%(8 / 113)$ of these samples showed a strong and full thickness staining. A strong and full thickness

TABLE II. Frequency of p16 Immunostaining Patterns in Cervical Neoplasia

\begin{tabular}{|c|c|c|c|c|c|c|}
\hline \multirow[b]{2}{*}{ Diagnosis } & \multirow[b]{2}{*}{ HPV status } & \multicolumn{4}{|c|}{ P16 staining ${ }^{a}$} & \multirow[b]{2}{*}{ Total } \\
\hline & & $1, \mathrm{n}(\%)$ & $2, \mathrm{n}(\%)$ & $3, \mathrm{n}(\%)$ & $4, \mathrm{n}(\%)$ & \\
\hline \multirow[t]{2}{*}{$<$ CIN2 $(\mathrm{n}=125)$} & HPV negative & $49(63)$ & $19(24)$ & $8(10)$ & $2(3)$ & $78(100)$ \\
\hline & HPV positive & $15(32)$ & $20(43)$ & $3(6)$ & $9(19)$ & $47(100)$ \\
\hline \multirow[t]{2}{*}{ CIN2 $(\mathrm{n}=73)$} & HPV negative & $10(37)$ & $12(45)$ & $3(11)$ & $2(7)$ & $27(100)$ \\
\hline & HPV positive & $8(17)$ & $6(13)$ & $1(2)$ & $31(68)$ & $46(100)$ \\
\hline \multirow[t]{2}{*}{ CIN3 $(\mathrm{n}=72)$} & HPV negative & 0 & 0 & 0 & $2(100)$ & $2(100)$ \\
\hline & HPV positive & 0 & $2(3)$ & $1(1)$ & $67(96)$ & $70(100)$ \\
\hline \multirow[t]{2}{*}{ Cancer $(\mathrm{n}=25)$} & HPV negative & $5(83)$ & 0 & 0 & $1(17)$ & $6(100)$ \\
\hline & HPV positive & $1(5)$ & 0 & 0 & $18(95)$ & $19(100)$ \\
\hline Total & & $88(30)$ & $59(20)$ & $16(5)$ & $132(45)$ & $295(100)$ \\
\hline
\end{tabular}

HPV positive $=$ HPV $16,18,31,33,35,39,45,51,52,56,58,59,66$, and 68.

*Percentages of P16 staining are given in parenthesis.

${ }^{\mathrm{a}}$ The staining pattern for $\mathrm{p} 16^{\mathrm{INK} 4 \mathrm{a}}$ was graded 1-4 in each lesion as described in Materials and Methods. 
staining of $\mathrm{p} 16^{\mathrm{INK} 4 \mathrm{a}}$ was found in $68.6 \%(125 / 182)$ of the HPV positive samples. $2.7 \%$ of these samples (5/182) showed a diffuse and moderately positive staining, $15.3 \%(28 / 182)$ a rare basal $\mathrm{p} 16^{\mathrm{INK} 4 \mathrm{a}}$ staining, and a negative staining was observed for $13.1 \%$ (24/182) of the samples. As expected, $94.7 \%$ of the cervical cancers (18/19) and $84.4 \%$ of the high grade lesions (98/116) with a strong and full thickness staining for $\mathrm{p} 16^{\mathrm{INK} 4 \mathrm{a}}$ were positive for HPV. Independently of the HPV type, p16 $6^{\mathrm{INK} 4 \mathrm{a}}$ levels were similarly upregulated in cervical lesions (data not shown).

\section{DISCUSSION}

Studies from India indicate a high prevalence of HPV 16 and 18 in cervical cancer specimens as compared to the rest of the world. In 2009, a very high prevalence of HPV 16 has been reported in cervical cancers of women from Wardha, a rural area from central India [Gheit et al., 2009] in comparison to other geographical areas. HPV 16 was the predominant type present in $81.7 \%$ of the cases. So far, few studies reported such a high prevalence of HPV 16 in cervical cancer. Bhatla et al. [2008] performed a metaanalysis of several Indian studies from different regions and reported that HPV 16 was associated with $64.8 \%$ of invasive cervical cancers. In a study involving 119 cases of cervical cancer from South and East India, Peedicayil et al. [2006] reported HPV $16 / 18$ positivity in $75 \%$ of cases. Basu et al. [2009] reported that the HPV 16 and 18 prevalence in cervical cancer, either alone or combined, in four cities, that is, Kolkota (Eastern India), Delhi (North), Nagpur (Central), and Bangalore (South), accounted for $76.1 \%, 78.3 \%, 77.3 \%$, and $73.9 \%$ of cervical cancers, respectively. Pillai et al. [2010] based on a multicentric study in India involving 667 cervical cancer patients reported that HPV 16/18-positive fraction formed $79.6 \%$ of the cancer cases. In a recent study involving 108 cervical cancer specimens in the neighboring Sri Lanka, HPV types 16 and 18 accounted $83.4 \%$ of cases [Samarawickrema et al., 2011]. Recently, a meta-analysis performed by $\mathrm{Li}$ et al. [2011] of the HPV distribution in 30,848 invasive cervical cancers worldwide reported that the prevalence of HPV 16 in Western/Central Asia was 67\%, which was the highest prevalence compared to the other regions of the world.

In the present study, using a highly specific and sensitive HPV typing method [Gheit et al., 2006], a HPV DNA testing was performed on samples collected in Solapur district, a rural area of Central India (State of Maharashtra), from women with different cervical lesions grades and cervical cancers.

The overall prevalence of any HPV types in cervical cancers was $92 \%$ in the current study versus $93.3 \%$ for a previous study performed in Wardha [Gheit et al., 2009], which is consistent with the worldwide HPV prevalence in cervical cancers, ranking from $86 \%$ to $94 \%$ [Smith et al., 2007]. Overall, the most common type in single and multiple infections was HPV 16, which by far prevailed in all categories of cervical diseases, including grade 1 cervical intraepithelial neoplasia or inflammatory lesions (32.8\%), grade 2 cervical intraepithelial neoplasia (54.1\%), grade $3(76.4 \%)$, and cervical cancers (76.1\%). HPV 18 was the second most common type in cancer, and HPV 33 the second most common type in all precursor lesions. HPV types other than HPV 16, including HPV 18, were rarely found in single infections. However, it is important to underline that in our study the HPV prevalence in cervical cancer may have been underestimated due to the exclusion of specimens that tested beta globin negative $(n=86)$, of which 70 were cervical cancer.

The fraction of HPV 16/18 positive in women with cervical cancer and precursor lesions can be useful to estimate the benefits of HPV 16/18 prophylactic vaccines for the primary prevention of cervical neoplasia. In our study, the combined prevalence of oncogenic types HPV 16 and 18 increased, as expected, with the increasing severity of the cervical lesions, with more than $80 \%$ of women with invasive cervical cancer, whereas this fraction was found to account for $35.2 \%$ of the low grade lesions. This phenomenon has been well documented in other studies [Zerbini et al., 2001; Bhatla et al., 2006, 2008; Sandri et al., 2009].

These findings are in agreement with previous observations showing that, in general, the proportion of cervical cancer associated with HPV 16/18 is higher in Western/Central Asia (82\%) compared to other regions of the world (range: 70-76\%), including Eastern Asia (68\%) [Li et al., 2011]).

The present study provides novel evidence that, similarly to cervical cancer, HPV $16 / 18$ prevalence is consistently higher in Indian women, compared to women from elsewhere in the world, throughout all grades of cervical diseases. HPV 16/18 prevalence was actually higher in our study than in a meta-analysis of studies carried out in Europe and the Americas for grade 2 cervical intraepithelial neoplasia $(55.4 \%$ vs. $48.2 \%)$ and grade $3(77.8 \%$ vs. $61.5 \%)$ [Clifford et al., 2006]. These differences may partly be explained by the use in our study of a highly sensitive HPV genotyping method [Gheit et al., 2006; Schmitt et al., 2010]).

p16 ${ }^{\text {INK4a }}$, a cyclin dependent kinase-4 inhibitor expressed in a limited range of normal tissues and tumours has emerged as a valuable surrogate marker for high-risk HPV infection. As a biomarker of cellular transformation in cervical intraepithelial neoplasias, it is known to be accumulated in cells expressing the viral E7 oncoprotein [Dallenlenbach-Hellweg et al., 2004; O'Neill and McCluggage, 2006; Wentzensen and von Knebel Doeberitz, 2007]. This biomarker is used increasingly in several laboratories to improve the detection of high-grade cervical intraepithelial neoplasia and as a complement to current screening methods [Wentzensen et al., 2007; Bergeron et al., 2010]. The high level of inter-observer variability and a 
substantial number of false positive and false negative results associated with histopathologic interpretation of cervical intraepithelial neoplasia can be reduced by concomitant interpretation of $\mathrm{p} 16^{\mathrm{INK} 4 \mathrm{a}}$ staining. $\mathrm{p} 16^{\mathrm{INK} 4 \mathrm{a}}$ staining was used to evaluate if increased immunoexpression of this marker is observed with worsening grades of cervical intraepithelial neoplasia and invasive cancer in our study. In agreement with previous results from a recent meta-analysis [Tsoumpou et al., 2009], a correlation between the $\mathrm{p} 16^{\text {INK4a }}$ staining and the different grades of cervical intraepithelial neoplasia was observed. A strong and full thickness $\mathrm{p} 16^{\mathrm{INK} 4 \mathrm{a}}$ staining was observed only in $8.8 \%$ of the grade 1 cervical intraepithelial neoplasia or inflammatory lesions, compared to $45.2 \%$ of grade 2 , and to $95.8 \%$ of grade 3 , whereas $51.2 \%$ of the low grade lesions $(64 / 125)$ and $12.4 \%$ of the high grade cervical intraepithelial neoplasia (18/145) showed a negative $\mathrm{p} 16^{\mathrm{INK} 4 \mathrm{a}}$ staining, suggesting that $\mathrm{p} 16^{\mathrm{INK} 4 \mathrm{a}}$ staining alone may not be a good biomarker for high grade lesions which highlights the need to combine histopathology with the HPV DNA testing and/or the $\mathrm{p} 16^{\mathrm{INK} 4 \mathrm{a}}$ staining in order to decrease the rate of false negative results. The multiplex E7 PCR/APEX assay demonstrated $91.7 \%$ sensitivity for the prediction of grade 3 cervical intraepithelial neoplasia or worse (CIN3+), whereas the sensitivity of $\mathrm{p} 16^{\mathrm{INK} 4 \mathrm{a}}$ staining was $93.8 \%$. When $16^{\text {INK4a }}$ staining and HPV DNA assay were considered together a slight increase in sensitivity was observed at $94.6 \%$. The combination of multiplex E7 PCR/APEX assay and $\mathrm{p} 16^{\mathrm{INK} 4 \mathrm{a}}$ staining showed approximately $60 \%$, specificity for less than grade 2 cervical intraepithelial neoplasia, while a slightly lower specificity was observed for $\mathrm{p} 16^{\mathrm{INK} 4 \mathrm{a}}$ staining alone $(51 \%)$.

Only 25 cervical cancers, namely 19 squamous cell carcinomas and 6 adenocarcinomas, have been stained for $\mathrm{p} 16^{\mathrm{INK} 4 \mathrm{a}}$. No $\mathrm{p} 16^{\mathrm{INK} 4 \mathrm{a}}$ signal was observed in five adenocarcinoma and one squamous cell carcinoma. These results may be explained by misclassification of the cervical cancer. Indeed, it has been reported that p16 $6^{\text {INK4a }}$ immunostaining may be used to differentiate between cervical adenocarcinoma (diffusely positive) and endometroid-type endometrial adenocarcinoma (negative or focally positive) [O'Neill and McCluggage, 2006].

The HPV genotyping data from our study and other studies in India, showing a high HPV 16 and 18 prevalence in cervical cancer specimens in the country, strongly suggests that prophylactic HPV $16 / 18$ vaccination would significantly contribute in preventing cervical cancer in India. It is rather unfortunate that, in spite of substantial evidence that women in India could benefit from prophylactic HPV vaccines, the ambiguity and delays in quickly resolving the unfounded fears and controversies in certain quarters in India regarding its use, applications, efficacy and safety can lead to substantial damage for advancing cervical cancer prevention efforts in India, which contributes the major share of the global burden.

\section{ACKNOWLEDGMENTS}

We thank Mrs Annick Rivoire, Mrs Evelyn Bayle, and Mrs Krittika Guinot for their help in the preparation of this manuscript.

\section{REFERENCES}

Basu P, Roychowdhury S, Bafna UD, Chaudhury S, Kothari S, Sekhon R, Saranath D, Biswas S, Gronn P, Silva I, Siddiqi M, Ratnam S. 2009. Human papillomavirus genotype distribution in cervical cancer in India: Results from a multi-center study. Asian Pac J Cancer Prev 10:27-34.

Bergeron C, Ordi J, Schmidt D, Trunk MJ, Keller T, Ridder R. 2010. Conjunctive p16INK4a testing significantly increases accuracy in diagnosing high-grade cervical intraepithelial neoplasia. Am J Clin Pathol 133:395-406.

Bhatla N, Dar L, Patro AR, Kriplani A, Gulati A, Verma K, Broor S, Shah KV, Gravitt PE. 2006. Human papillomavirus type distribution in cervical cancer in Delhi, India. Int J Gynecol Pathol 25:398-402.

Bhatla N, Dar L, Rajkumar PA, Kumar P, Pati SK, Kriplani A, Gulati A, Broor S, Iyer VK, Mathur S, Shah KV, Gravitt PE. 2008. Human papillomavirus-type distribution in women with and without cervical neoplasia in north India. Int $\mathrm{J}$ Gynecol Pathol 27:426-430.

Clifford G, Franceschi S, Diaz M, Munoz N, Villa LL. 2006. Chapter 3: HPV type-distribution in women with and without cervical neoplastic diseases. Vaccine 24:S3-26-S3-34.

Cogliano V, Baan R, Straif K, Grosse Y, Secretan B, El GF. 2005 Carcinogenicity of human papillomaviruses. Lancet Oncol 6:204.

Dallenlenbach-Hellweg G, Trunk MJ, von Knebel Doeberitz M, 2004. Traditional and new molecular methods for early detection of cervical cancer. Arkh Patol 66:35-39.

Einstein MH, Schiller JT, Viscidi RP, Strickler HD, Coursaget P, Tan T, Halsey N, Jenkins D. 2009. Clinician's guide to human papillomavirus immunology: Knowns and unknowns. Lancet Infect Dis 9:347-356.

Eklund C, Zhou T, Dillner J. 2010. Global proficiency study of human papillomavirus genotyping. J Clin Microbiol 48:4147-4155.

Ferlay J, Shin HR, Bray F, Forman D, Mathers C, Parkin DM. 2010. Estimates of worldwide burden of cancer in 2008 GLOBOCAN 2008. Int J Cancer 127:2893-2917.

Gheit T, Landi S, Gemignani F, Snijders PJ, Vaccarella S, Franceschi S, Canzian F, Tommasino M. 2006. Development of a sensitive and specific assay combining multiplex PCR and DNA microarray primer extension to detect high-risk mucosal human papillomavirus types. J Clin Microbiol 44:2025-2031.

Gheit T, Vaccarella S, Schmitt M, Pawlita M, Franceschi S, Sankaranarayanan R, Sylla BS, Tommasino M, Gangane N. 2009. Prevalence of human papillomavirus types in cervical and oral cancers in central India. Vaccine 27:636-639.

IARC. IARC Monographs on the Evaluation of Carcinogenic Risks to Humans IARC Monographs, Volume 90. International Agency for Research on Cancer, Lyon; 2007.

Li N, Franceschi S, Howell-Jones R, Snijders PJ, Clifford GM. 2011. Human papillomavirus type distribution in 30,848 invasive cervical cancers worldwide: Variation by geographical region, histological type and year of publication. Int J Cancer 128:927-935.

Lu B, Kumar A, Castellsague X, Giuliano AR. 2011. Efficacy and safety of prophylactic vaccines against cervical HPV infection and diseases among women: A systematic review and metaanalysis. BMC Infect Dis 11:13.

National Cancer Registry Program of India. Two-year report of population based cancer registries 2004-2005. http://www.pbcrindia. org/Pbcr_map1.htm. Accessed on April 3, 2011.

O’Neill CJ, McCluggage WG. 2006. p16 expression in the female genital tract and its value in diagnosis. Adv Anat Pathol 13: 8-15.

Peedicayil A, Abraham P, Sathish N, John S, Shah K, Sridharan G, Gravitt P. 2006. Human papillomavirus genotypes associated with cervical neoplasia in India. Int J Gynecol Cancer 16:15911595.

Pillai RM, Babu JM, Jissa VT, Lakshmi S, Chiplunkar SV, Patkar M, Tongaonkar H, Reddy KB, Chakka KN, Siddiqui M, Roychoudury S, Abraham P, Peedicayil A, Gnanamony M, Subashini J, 
Ram TS, Dey B, Singh N, Singh A, Jain SK, Jayshree RS. 2010. Region-wise distribution of high-risk human papillomavirus types in squamous cell carcinomas of the cervix in India. Int $J$ Gynecol Cancer 20:1046-1051.

Romanowski B, de Borba PC, Naud PS, Roteli-Martins CM, De Carvalho NS, Teixeira JC, Aoki F, Ramjattan B, Shier RM, Somani R, Barbier S, Blatter MM, Chambers C, Ferris D, Gall SA, Guerra FA, Harper DM, Hedrick JA, Henry DC, Korn AP, Kroll R, Moscicki AB, Rosenfeld WD, Sullivan BJ, Thorning CS. 2009. Sustained efficacy and immunogenicity of the human papillomavirus (HPV)-16/18 AS04-adjuvanted vaccine: Analysis of a randomised placebo-controlled trial up to 6.4 years. Lancet 374:1975-1985.

Saiki RK, Gelfand DH, Stoffel S, Scharf SJ, Higuchi R, Horn GT, Mullis KB, Erlich HA. 1988. Primer-directed enzymatic amplification of DNA with a thermostable DNA polymerase. Science 239:487-491.

Samarawickrema NA, Tabrizi SN, Hewavisenthi J, Leong T, Garland SM. 2011. Distribution of human papillomavirus genotypes in archival cervical tissue from women with cervical cancer in urban Sri Lanka. Int J Gynaecol Obstet 115:180-182.

Sandri MT, Riggio D, Salvatici M, Passerini R, Zorzino L, Boveri S, Radice D, Spolti N, Sideri M. 2009. Typing of human papillomavirus in women with cervical lesions: Prevalence and distribution of different genotypes. J Med Virol 81:271-277.

Sankaranarayanan R. 2012. "See-and-treat" works for cervical cancer prevention: What about controlling the high burden in India? Ind J Med Res (In press).

Sankaranarayanan R, Bhatla N, Gravitt PE, Basu P, Esmy PO, Ashrafunnessa KS, Ariyaratne Y, Shah A, Nene BM. 2008. Human papillomavirus infection and cervical cancer prevention in India, Bangladesh, Sri Lanka and Nepal. Vaccine 26:M43-M52.

Schmitt M, Dondog B, Waterboer T, Pawlita M, Tommasino M, Gheit T. 2010. Abundance of multiple high-risk human papillomavirus (HPV) infections found in cervical cells analyzed by use of an ultrasensitive HPV genotyping assay. J Clin Microbiol $48: 143-149$.
Smith JS, Lindsay L, Hoots B, Keys J, Franceschi S, Winer R, Clifford GM. 2007. Human papillomavirus type distribution in invasive cervical cancer and high-grade cervical lesions: A metaanalysis update. Int $\mathrm{J}$ Cancer 121:621-632.

Schiffman M, Clifford G, Buonaguro FM. 2009. Classification of weakly carcinogenic human papillomavirus types: Addressing the limits of epidemiology at the borderline. Infect Agent Cancer $4: 8$

Tsoumpou I, Arbyn M, Kyrgiou M, Wentzensen N, Koliopoulos G, Martin-Hirsch P, Malamou-Mitsi V, Paraskevaidis E. 2009. p16(INK4a) immunostaining in cytological and histological specimens from the uterine cervix: A systematic review and metaanalysis. Cancer Treat Rev 35:210-220.

Villa LL, Costa RL, Petta CA, Andrade RP, Paaavonen J, Iversen OE, Olsson SE, Hoye J, Steinwall M, Riis-Johannessen G, Andersson-Ellstrom A, Elfgren $\mathrm{K}$, Krogh G, Lehtinen M, Malm C, Tamms GM, Giocoletti K, Lupinacci L, Railkar R, Taddeo FJ, Bryan J, Esser MT, Sings HL, Saah AJ, Barr E. 2006. High sustained efficacy of a prophylactic quadrivalent human papillomavirus types 6/11/16/18 L1 virus-like particle vaccine through 5 years of follow-up. Br J Cancer 95:14591466 .

Walboomers JM, Jacobs MV, Manos MM, Bosch FX, Kummer JA, Shah KV, Snijders PJ, Peto J, Meijer CJ, Muñoz N. 1999 Human papillomavirus is a necessary cause of invasive cervical cancer worldwide. J Pathol 189:12-19.

Wentzensen N, Bergeron C, Cas F, Vinokurova S, von Knebel DM. 2007. Triage of women with ASCUS and LSIL cytology: Use of qualitative assessment of p16INK4a positive cells to identify patients with high-grade cervical intraepithelial neoplasia. Cancer 111:58-66.

Wentzensen N, von Knebel Doeberitz M. 2007. Biomarkers in cervical cancer screening. Dis Markers 23:315-330.

Zerbini M, Venturoli S, Cricca M, Gallinella G, De SP, Costa S, Santini D, Musiani M. 2001. Distribution and viral load of type specific HPVs in different cervical lesions as detected by PCRELISA. J Clin Pathol 54:377-380. 